\title{
Extraction of membrane antigens from Brucella ovis and an assessment of their serological activity by immunoblotting
}

\author{
JAMES CHIN* and BERNADETTE TURNER
}

Immunology Section, Elizabeth Macarthur Agricultural Institute, New South Wales Agriculture and Fisheries, PMB 8, Camden NSW 2570, Australia

(Received 24 January 1990; revised 29 March 1990; accepted 2 April 1990)

\begin{abstract}
The efficacy and selectivity of chaotropic and phase-partitioning procedures for the extraction of membrane proteins from Brucella ovis were compared with a standard Sarkosyl method. Major group 1, 2 and 3 outermembrane proteins (OMPs) of $B$. ovis stained by Coomassie blue in SDS-PAGE gels had, respectively, apparent molecular masses of 81/82 kDa, 39-41 kDa and 30-32 kDa. The presence of these bands in the Sarkosyl extract of total membrane vesicles (TMVs) indicate that the procedure failed to selectively solubilize only inner-membrane proteins (IMPs). SDS-PAGE analyses also revealed the presence of OMPs and other additional bands following extraction of $B$. ovis TMVs by butanol phase-partitioning or with extraction solutions based on the chaotropic reagents potassium thiocyanate (KSCN), sodium salicylate (SSC) and lithium acetate (LAE). OMPs are therefore not selectively extracted by any one of these procedures. Based on the number and staining intensity of extracted membrane-associated polypeptides, the efficacy of different extraction procedures could be graded in decreasing order as follows: KSCN, SSC, butanol and LAE. Both butanol and SSC were particularly effective in extracting group 3 OMPs. Sera from chronic excretor rams were used to identify zones of seroreactivity in immunoblots. Essentially, two reactivity patterns were seen: strong antibody binding against polypeptides in zones A (46$85 \mathrm{kDa}), \mathrm{C}(28-32 \mathrm{kDa})$ and $\mathrm{D}(18-22 \mathrm{kDa})$ in one, and additional reactivity against zones $\mathrm{B}(34-44 \mathrm{kDa})$ and $\mathrm{E}$ (13-18 kDa) polypeptides in the other. Irrespective of the method of membrane extraction, immunoblots using pooled ram sera collected from flocks with ovine brucellosis, and grouped on the basis of increasing complement fixation titre, displayed more intense reactivity against an increasing number of polypeptide bands. Membrane antigens extracted with KSCN and Sarkosyl possessed strong immunoblot reactivity in all five zones while OMPs generally showed the weakest reactivity. In contrast, immunoblot activity of polypeptides in SSC, butanol and LAE extracts were clustered in zones A, C, D and E. It is concluded that chaotropic and organic phase-partitioning procedures do not selectively extract OMPs from $B$. ovis but represent simple and efficacious methods for generating antigen preparations enriched in membrane polypeptides.
\end{abstract}

\section{Introduction}

Ovine brucellosis is considered, worldwide, to be an economically important disease of sheep (Burgess, 1982). The aetologic agent for this venereally transmitted disease (Hartley, 1955; McGowan \& Schultz, 1956) is a facultative intracellular Gram-negative bacterium, Brucella ovis (Bulgin et al., 1983). Eradication and accreditation schemes provide the most effective form of control, and monitoring programmes are carried out using the

Abbreviations: CF, complement fixation; OMVs, outer-membrane vesicles; TMVs, total membrane vesicles; IMPs, inner-membrane proteins; OMPs, outer-membrane proteins; LAE, lithium acetate; SSC, sodium salicylate; KDO, ketodeoxyoctonic acid (3-deoxy-Dmanno-octulosonic acid); SDH, succinic dehydrogenase. complement fixation (CF) test. The CF test antigen is routinely prepared by hot saline extraction of bacteria (Myers et al., 1972). The antigenic composition of such preparations is extremely heterogeneous for they contain membrane as well as cytoplasmic proteins (unpublished results). In addition, denaturation of cellular antigens during heat extraction may be one of the reasons for the aberrant serological responses associated with the use of the CF test (Hicks et al., 1978).

Recent attempts at improving serological detection of ovine brucellosis have focused on the use of purified membrane antigens (Riezu-Boj et al., 1986; Afzal et al., 1987). For example, proteins extracted with detergent from total membrane or outer-membrane vesicles (OMVs) of B. ovis have been used in ELISA (Chin \& 
Scully, 1986). However, preparation of inner- and outermembranes generally requires differential density gradient centrifugation and several reports in the literature suggest that chaotropic agents such as lithium acetate (Heckels, 1981; Chin, 1983), sodium salicylate (Donachie et al., 1984) and potassium thiocyanate (Ryu \& Kaeberle, 1986; Chin et al., 1983) may provide simpler alternatives for their purification. Other procedures including organic phase-partitioning with butanol (Goldman et al., 1981) or chloroform/methanol (Chin \& Dai, 1990) can provide a more selective method for the extraction of outer-membrane proteins (OMPs) from Gram-negative bacteria, but the efficacy of these and previous procedures have not been fully evaluated with B. ovis. This paper compares chaotropic- and butanolextraction procedures with the Sarkosyl/sucrose-gradient protocol of Filip et al. (1973) for the extraction of OMPs of $B$. ovis. The serological reactivities of various membrane preparations have also been analysed by immunoblotting using sera from excretor rams or sera sampled from rams belonging to flocks with a known history of ovine brucellosis.

\section{Methods}

Bacterial strains, cultivation and harvest. Lyophilized stock cultures of a primary field isolate of $B$. ovis (strain Bo301) were revived from ampoules by resuspension in Brain Heart Infusion broth (Oxoid), and subcultured onto Blood agar base no. 2 (Oxoid) supplemented with sheep serum and Difco Bacto-agar at a final concentration of $10 \%(\mathrm{v} / \mathrm{v})$ and $2 \%(\mathrm{w} / \mathrm{v})$ respectively (Chin, 1983). Expanded cultures were obtained by a further subculture onto large Petri Dishes $(18.5 \mathrm{~cm}$ diameter) which were maintained for $5 \mathrm{~d}$ at $37^{\circ} \mathrm{C}$ in a $10 \%(\mathrm{v} / \mathrm{v}) \mathrm{CO}_{2}-$ in-air mixture. Bacteria were harvested from plates with sterile saline $(0.85 \% \mathrm{NaCl})$ and washed twice prior to extraction.

Cell breakage. Total cell homogenates were prepared by disruption in a French pressure cell as described by Chin \& Scully (1986).

Isolation of membrane vesicles. Cellular debris and particulate matter in the total cell homogenate was removed by low speed centrifugation at $10000 \mathrm{~g}$. Total membrane vesicles (TMVs) in the supernatant were recovered by ultracentrifugation at $150000 \mathrm{~g}$ for $90 \mathrm{~min}$ through a sucrose pad (Chin \& Dai, 1990).

Inner- and outer-membrane proteins. Inner-membrane proteins (IMPs) were extracted from TMVs with Sarkosyl (Filip et al., 1973) and OMVs were recovered by differential ultracentrifugation in a discontinuous sucrose gradient as described by Schnaitman (1970, 1971). IMPs at the top of the sucrose gradient were dialysed extensively against gel electrophoresis buffer while OMVs were diluted with water and pelleted by uitracentrifugation at $100000 \mathrm{~g}$. OMPs are those polypeptides associated with the OMVs.

Butanol extraction. Bacteria were suspended in 10 vols of saline before the addition of an equal volume of water-saturated butanol (Goldman et al., 1981). The mixture was stirred overnight (200 r.p.m.) at $4{ }^{\circ} \mathrm{C}$.

Sodium salicylate, potassium thiocyanate or lithium acetate extraction. Freshly harvested and washed bacteria were suspended in $10 \mathrm{vols}$ of extraction solution - SSC (1 M-sodium salicylate, pH 5.9), KSCN $(0.5 \mathrm{M}$-potassium thiocyanate $+0.08 \mathrm{M}-\mathrm{NaCl}, \mathrm{pH} 6.8)$ or LAE $(0.2 \mathrm{M}$ lithium acetate $\left.+10 \mathrm{mM}-\mathrm{Na}_{2} \mathrm{EDTA}, \mathrm{pH} 6 \cdot 3\right)$ and stirred overnight at $4{ }^{\circ} \mathrm{C}$.

Treatment of cellular extracts. Cell debris in the extracts were removed by centrifugation at $10000 \mathrm{~g}$ and each supernatant was dialysed extensively against saline. The dialysate was concentrated by ultrafiltration through Diaflo (Amicon) PM30 to about one-tenth the extraction volume and TMVs were pelleted $(100000 \mathrm{~g})$ in a table-top mini-ultracentrifuge (TL100.3, Beckman). The clear gelatinous pellet was rinsed with cold distilled water and resuspended in electrophoresis buffer for SDS-PAGE.

$S D S-P A G E$. Protein electrophoresis was done in the mini-gel system (Hoeffer, Calif., USA) under reducing conditions as described by Laemmli (1970). Membrane vesicles and membrane proteins were heated at $100^{\circ} \mathrm{C}$ for $5 \mathrm{~min}$ in the presence of SDS and mercaptoethanol in Tris/glycine buffer being loaded onto a $12 \%(\mathrm{w} / \mathrm{v})$ acrylamide running gel with a $4 \%(w / v)$ stacking gel. Electrophoresis was run at a constant $120 \mathrm{~V}$ until the bromophenol blue tracking dye had migrated to the bottom of the gel. Polypeptide bands were stained with Coomassie Brilliant Blue.

Immunoblotting. Polypeptides were transferred electrophoretically from the acrylamide gel to nitrocellulose paper in a Bio-Rad Trans-Blot apparatus under conditions essentially similar to those described by Towbin et al. (1979) except that propan-2-ol was used instead of methanol. Immunoblots were blocked by incubation in highsalt/Tween $(25 \mathrm{~mm}$-Tris/HCl, pH 8.9;0.15 M- NaCl; $0.5 \%$, v/v, Tween 20), washed in TSTw (20 mM-Tris/HCl, pH 7.4; $0.015 \mathrm{M}-\mathrm{NaCl} ; 0.01 \%$, $\mathrm{v} / \mathrm{v}$, Tween 20) and then reacted with ram serum diluted in TSTw. Antibody binding to antigens on the nitrocellulose was done with a Decaprobe apparatus (Hoefer). Ovine antibodies which bound to polypeptides on the nitrocellulose were located by reaction with alkaline-phosphatase-conjugated anti-ruminant immunoglobulinspecific monoclonal antibody (Chin \& Watts, 1988).

Sera. These were collected from six excretor rams whose semen cultures yielded growth of $B$. ovis. Field sera were sampled from rams belonging to flocks with a known history of ovine brucellosis. However, the infective status of these rams was unknown. CF titres of field sera were determined according to Searson (1982), and pooled into six categories equivalent to titres of $0,8,16,32,64$ and 128 .

Chemical analysis. Total dry weights of cells or pelleted membrane vesicles were determined after lyophilization. Total protein was estimated by the Lowry method with BSA as standard. Total carbohydrate was assessed by the phenol/sulphuric acid method of Dubois et al. (1956) with glucose as standard. Ketodeoxyoctonic acid (KDO) was measured by the method of Osborn (1963). Succinate dehydrogenase (SDH) activity was assayed according to Osborn et al. (1972).

\section{Results}

\section{Chemical composition of membrane vesicles}

The protein, carbohydrate and KDO content of membrane vesicles obtained by ultracentrifugation of chaotropic, butanol or Sarkosyl extracts is given in Table 1. The protein content of membrane vesicles extracted by various procedures can be sorted in decreasing order as follows: KSCN $>$ SSC $>$ butanol $>$ LAE $>$ Sarkosyl. 
Table 1. Chemical composition of membrane vesicles extracted by chaotropic treatments, butanol phasepartitioning, or Sarkosyl treatment of total membrane vesicles

The data represent the means of triplicate determinations from at least two separate extractions.

\begin{tabular}{lcccc}
\hline \hline $\begin{array}{l}\text { Extraction } \\
\text { method }\end{array}$ & Protein* & Carbohydrate* & KDO $^{*}$ & SDH $^{\dagger}$ \\
\hline KSCN & $35-42$ & $3-6$ & $0.5-0.8$ & $1 \cdot 19$ \\
SSC & $32-38$ & $2-7$ & $0 \cdot 3-0.6$ & 0.93 \\
Butanol & $10-20$ & $10-15$ & $0 \cdot 9-1 \cdot 1$ & $<0 \cdot 2$ \\
LAE & $15-23$ & $7-12$ & $0 \cdot 4$ & $1 \cdot 25$ \\
Sarkosyl & $5-9$ & $11-17$ & $1 \cdot 3$ & $0 \cdot 7$ \\
\hline \hline
\end{tabular}

* Percentage dry wt of bacteria.

$\dagger$ Specific activity expressed as $\Delta A_{600} \min ^{-1}$ (mg protein) $)^{-1}$.

An enrichment of OMVs in the Sarkosyl and butanol fractions was paralleled by higher KDO values and lower SDH activity compared to other extraction protocols. Membrane vesicles extracted by KSCN and SSC procedures resulted in relatively high levels of KDO and $\mathrm{SDH}$. Inner membrane enrichment in the LAE fraction was indicated by the high $\mathrm{SDH}: \mathrm{KDO}$ ratio.

\section{SDS-PAGE profiles}

The polypeptide banding profile of membrane vesicles extracted by chaotropic treatment or butanol phasepartitioning of intact bacteria is depicted in Fig. 1. SSC (lane $a$ ) extracted major polypeptide bands located at 24 , $25-27$ and $29 \mathrm{kDa}$, and ten other prominent but not as intensely stained bands at $81,62,60,57,44,43,40,35$,
17-18 and $15 \mathrm{kDa}$. Major bands extracted by KSCN (lane $b$ ) were located by $17,27,29,35,39-40,45,50,55-$ 57 and $60 \mathrm{kDa}$. Nine intensely stained bands were generated by butanol treatment and these were at 57,40 , $35,29-30,25-27,24,19,18$ and $17 \mathrm{kDa}$ respectively (lane c). Only a single darkly stained band $(27 \mathrm{kDa})$ was extracted by LAE (lane $d$ ) with less prominent bands at $81,79,60,57,44,40,35,30,29$ and $25 \mathrm{kDa}$.

Major polypeptides associated with OMVs left behind after Sarkosyl extraction were located at 80, 66, 40, 29$30,19,17.5$ and $15 \mathrm{kDa}$ (Fig. 1, lane g). However, IMPs extracted by Sarkosyl also had a similar banding pattern (Fig. 1, lane $f$ ) except that some of these bands were more deeply stained (e.g. $29-30 \mathrm{kDa}$ band in Fig. 1, lane $f$ compared with lane $g$ ). SDS-PAGE of whole bacteria, run as a positive control, showed the presence of major bands at $81,66,58,55,41,39,35,29-30,27,20$ and $14 \mathrm{kDa}$ (lane $e$ ).

\section{Antibody response of infected rams}

Sera from six infected rams were used initially to identify serologically reactive polypeptides associated with membrane vesicles extracted by various procedures. On the basis of reactivity against whole bacterial antigens (Fig. 2, lane $a$ ), Sarkosyl-insoluble (OMPs) or Sarkosyl-soluble (IMPs) polypeptides (lane $b$ and $c$ respectively), LAE (lane $d$ ), KSCN (lane $e$ ) or SSC (lane $f$ ) extracts, two reactivity patterns were consistently obtained. These are represented in Fig. 2 by ram I (upper panel) and ram II (lower panel) respectively. Four of the six rams (exemplified by ram I) reacted strongly against bands $(81,74,66$,

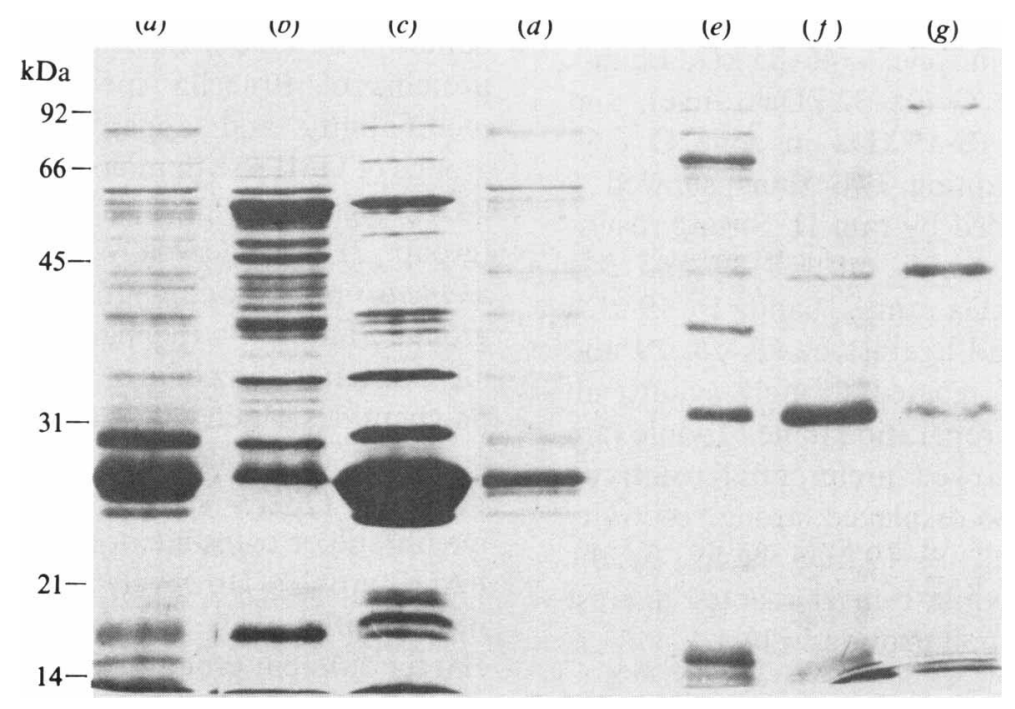

Fig. 1. SDS-PAGE profiles of B. ovis membrane antigens. Approximately $50 \mu \mathrm{g}$ of antigen per lane was loaded onto $12 \%$ (w/v) acrylamide gels and stained with Coomassie Blue. Lanes represent total membrane vesicles extracted by $(a)$ SSC, $(b) \mathrm{KSCN},(c)$ butanol and $(d)$ LAE reagents respectively. Whole bacteria, Sarkosyl-extracted IMPs and OMPs are represented by lanes $(e),(f)$ and $(g)$ respectively. 


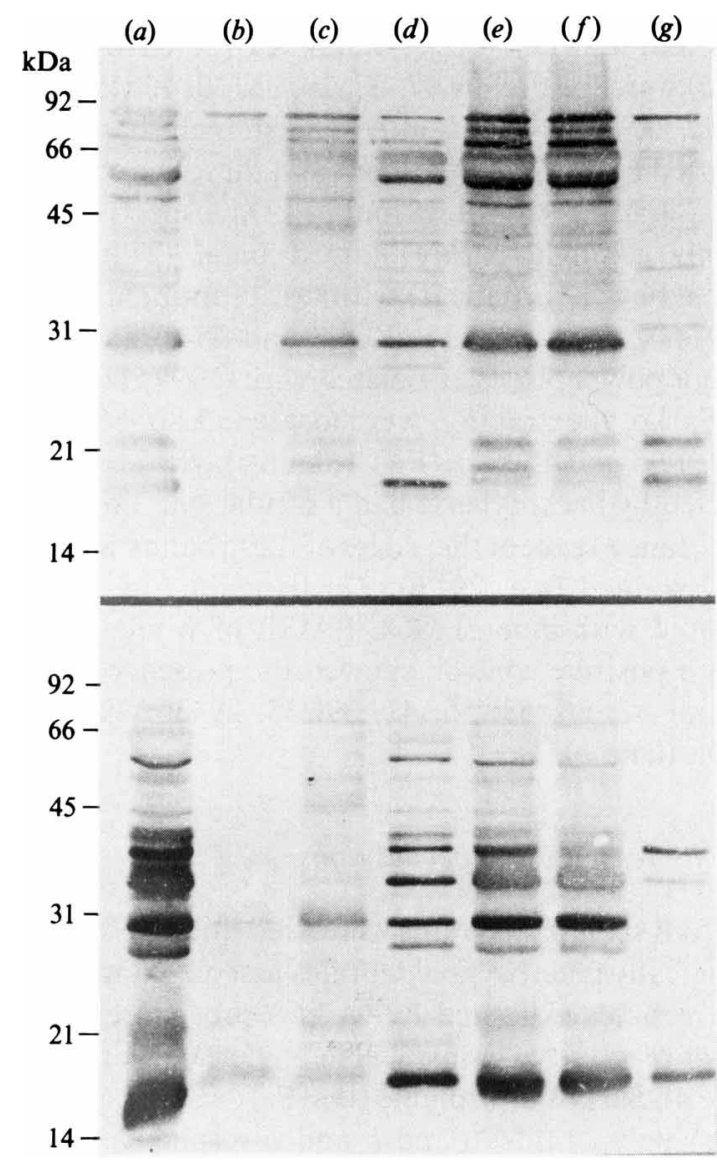

Fig. 2. Immunoblot reactivity profiles of infected rams against $B$. ovis antigens. Whole bacteria (a), OMPs $(b)$, IMPs $(c)$, and membrane vesicles extracted by LAE $(d), \operatorname{KSCN}(e), \operatorname{SSC}(f)$ or butanol $(g)$, were loaded onto $12 \%(\mathrm{w} / \mathrm{v})$ acrylamide gels and electrophoresed before Western blot transfer onto nitrocellulose. Two typical reactivity patterns (upper and lower panels) are shown using serum from rams I and II respectively.

54-56 and $46 \mathrm{kDa}$ ) located in zone $\mathrm{A}$ (46-85 $\mathrm{kDa}$ range), bands $29-30 \mathrm{kDa}$ in zone $\mathrm{C}(28-32 \mathrm{kDa}$ range), and bands $20-21,19-20$ and $18-19 \mathrm{kDa}$ in zone $\mathrm{D}(18-$ $22 \mathrm{kDa}$ range). The remaining two rams showed a reactivity pattern exemplified by ram II. Strong reactivity was evident against bands $(40,38-39$ and $34-$ $36 \mathrm{kDa}$ ) in zone $\mathrm{B}(34-44 \mathrm{kDa}$ range), bands $16-19 \mathrm{kDa}$ in zone $\mathrm{E}(13-18 \mathrm{kDa})$, and against bands 28,29 and $30 \mathrm{kDa}$ in zone $\mathrm{C}$. Ram I reacted strongly against an $81 \mathrm{kDa}$ band in the OMP preparation (lane $b$ ) while ram II failed to do so and showed preferential reactivity against zone E. Ram I also displayed strong reactivity against the $81,20-21$ and $18-19 \mathrm{kDa}$ bands in the butanol extract (lane $g$ ), while ram II reacted against $38-39,35$ and $18-19 \mathrm{kDa}$ polypeptides.

\section{Relationship between $C F$ titre and immunoblot reactivity}

The effect of increasing CF titre on immunoblot reactivity was examined using pooled sera. Each pool contained serum from four rams with identical titre; these were randomly selected from field sera submitted to our diagnostic laboratory. Figs 3, 4, 5 and 6 depict immunoblot reactivity against membrane antigens extracted by SSC, KSCN, butanol and LAE respectively, while Fig. 7 shows the reactivity against Sarkosylextracted antigens and OMPs. All of these Figures show that the number of reactive bands as well as the intensity of reactivity against membrane antigens increased with rising $\mathrm{CF}$ titre. In the case of pooled sera with high $\mathrm{CF}$ titres of 64 and 128, the intensity of blot reactivity was poorest against OMPs (Fig. 7, lanes $j$ and $k$ ) and strongest against polypeptides extracted with $\mathrm{KSCN}$ (Fig. 4, lanes $d$ and $e$ ). Sera with low CF titres of 8 and 16 reacted best against membrane antigens extracted by KSCN and butanol (lanes $a$ and $b$ in Figs 4 and 5). Strong reactivity against zone $A$ polypeptides was seen in blots utilizing membrane antigens extracted by KSCN, LAE and Sarkosyl, while zone B reactivities were strongest with antigens extracted by KSCN (Fig. 4) and Sarkosyl (Fig. 7). Sera also reacted prominently against a $31 \mathrm{kDa}$ band (zone C) present in OMPs (Fig. 7, lane $k$ ), LAE (Fig. 6, lanes $c-e$ ) and Sarkosyl extracts (Fig. 7, lanes $d-$ $e$ ). However, reactivity in zone $\mathrm{C}$ was directed against different bands located at $28-30 \mathrm{kDa}$ for antigens extracted with SSC (Fig. 3), KSCN (Fig. 4) and butanol (Fig. 5). Membrane antigens extracted by all procedures under evaluation showed strong serological reactivity in zones $\mathrm{D}$ and $\mathrm{E}$.

\section{Discussion}

Santos et al. (1984) classified outer-membrane or porin proteins of Brucella species on the basis of heatmodifiability and apparent molecular mass. Three groups of OMPs with molecular masses in the range 88$94 \mathrm{kDa}$ (group 1), 35-39 kDa (group 2) and 25-31 kDa (group 3) are generally recognized. Only Brucella melitensis possesses an additional $48 \mathrm{kDa}$ band between groups 1 and 2. On this basis, it is clear from Fig. 1 that all extraction procedures tested were able to extract polypeptides which band at positions equivalent to OMP groups 1-3. None of these procedures selectively extracted OMPs since other polypeptides of innermembrane or cytosolic origin were present in the SDSPAGE profiles. However, there were notable differences in the ability of the chaotropic reagents and butanol to extract different group 1, 2 or 3 OMPs. Using KDO and SDH as markers for OMVs and IMPs respectively, the data in Table 1 also support the view that different extraction procedures are not selective in the extraction of either inner or outer membranes. 
Chaotropic reagents such as sodium salicylate (Donachie et al., 1984) and potassium thiocyanate (Ryu \& Kaeberle, 1986) have been used to extract cell-surface antigens of Pasteurella species for antigenic analyses. However, the identities of OMPs extracted by these procedures have not been compared with traditional and more laborious methods (Osborn et al., 1972; Filip et al., 1973; Hancock \& Nikaido, 1978). With B. ovis, SSC and KSCN extracted a broader range of polypeptides even though every attempt was made to minimize cytosolic components by only pelleting membrane vesicles present in the extracts (see Methods). SDS-PAGE revealed that SSC and KSCN extracted membrane polypeptides of similar and unique apparent molecular mass. For example, the former reagent extracted major seroreactive bands that were primarily located in zone $\mathrm{C}$, while the latter extracted polypeptides that were prominent in all five zones. Both these reagents extracted a darkly stained Coomassie band of apparent molecular mass $28 / 29 \mathrm{kDa}$ that was also present in inner- and outermembrane extracts. The butanol protocol was extremely efficacious in extracting a similar $28 / 29 \mathrm{kDa}$ band from B. ovis. However, the $28 / 29 \mathrm{kDa}$ band appears to be serologically unreactive (Fig. 2) in comparison to the $29 / 30 \mathrm{kDa}$ band in zone $\mathrm{C}$. This band is not a major Coomassie-blue-stained band in IMP and OMP preparations even though it is very distinctive in SSC, KSCN and butanol extracts. It is likely that both these zone $\mathrm{C}$ bands correspond with group 3 OMPs (Gamazo et al., 1989; Afzal et al., 1987). However, only Gamazo et al. (1989) have demonstrated strong immunoblot reactivity against the 29/30 kDa band.

The primary encounter between host immune cells and invading bacteria is a surface recognition phenomenon (Costerton et al., 1981). It is likely that rams exposed to $B$. ovis generally mount a humoral response targetted primarily against surface antigens of these bacteria. Evidence for this was obtained previously (Chin \& Plant, 1989) when a whole cell ELISA was used to assay for antibodies against predominantly surface determinants in infected rams. Intracellular uptake and survival of cells within the reticulo-endothelial system (Ficht et al., 1988) would limit further antigenic exposure until the proliferative phase of the disease when the organisms are released in the reproductive tract. This may be one of the reasons why excretor rams (Fig. 2) recognize a wider repertoire of subunit antigens present in all extracts compared to field sera which have been collected from rams whose infective status is unknown (Figs 3-7 and unpublished data). In fact, some of the field sera may actually represent samplings taken at times equivalent to whole cell ELISA rise and fall stages of abortively infected rams (Chin \& Plant, 1989).

Compared to other membrane antigens, the serologi- cal activity of subunit polypeptides associated with Sarkosyl-extracted OMVs showed consistently low reactivity in immunoblots against sera from excretor rams and field sera. It is difficult to reconcile this observation with the high levels of ELISA reactivity against cell surface determinants in rams that have been exposed to B. ovis (Chin \& Plant, 1989) and may reflect preferential antibody binding to native (e.g. LPS and associated proteins) rather than denatured outer-membrane polypeptides generated by mercaptoethanol/heat treatment. Alternatively, the low reactivity associated with OMP preparations may be the consequence of a lower concentration of outer-membrane epitopes because these have been extracted by Sarkosyl. Some support for this is seen in Fig. 1 where the SDS-PAGE profiles show a close similarity between inner- (lane $f$ ) and outer- (lane $g$ ) membrane proteins extracted by the Sarkosyl procedure. Although extraction of IMPs by Sarkosyl is comparatively selective in many Gram-negative species (Page \& Taylor, 1988; Chin \& Dai, 1990), it does not appear to be as selective with Brucella species (Verstreate et al., 1982). Further evidence that OMPs may have been extracted by Sarkosyl is seen in the immunoblot profiles in Fig. 7. Reactivity against group 2 OMPs with apparent molecular masses of $41-43 \mathrm{kDa}$ is absent in OMP (lanes $j$ and $k$ ) but is present in IMP preparations (lanes $e$ and $f$ ) in zone B.

On the basis of these results, it can be concluded that chaotropic and butanol protocols do not selectively remove OMPs from intact $B$. ovis. This may be due to the tendency for $B$. ovis to form extracellular blebs (Gamazo et al., 1989). The higher protein content of membrane vesicles extracted by chaotropic reagents lends support to the hypothesis that these protocols enhance blebbing (Table 1). Differences in the polypeptide fingerprints of pellets from various extracts would probably reflect either selective loss of stripped membrane antigens or exclusion from the intravesicular micelle environment. Since the cytosol may be entrapped during the blebbing process, it is likely that membrane vesicles contain extraneous proteins in addition to inner- and outermembrane proteins. Evidence for this is seen in immunoblots where field sera and sera from excretor rams displayed essentially similar reactivity patterns in the five major zones irrespective of the extraction protocol used.

Butanol phase-partitioning and chaotropic extraction protocols do provide a simpler and more efficacious alternative for extracting membrane antigens than the Sarkosyl procedure of Filip et al. (1973). This is particularly important in the light of data presented here which show that IMPs are not selectively extracted by Sarkosyl and are contaminated by OMPs. Therefore the Filip procedure confers no additional advantage for the 


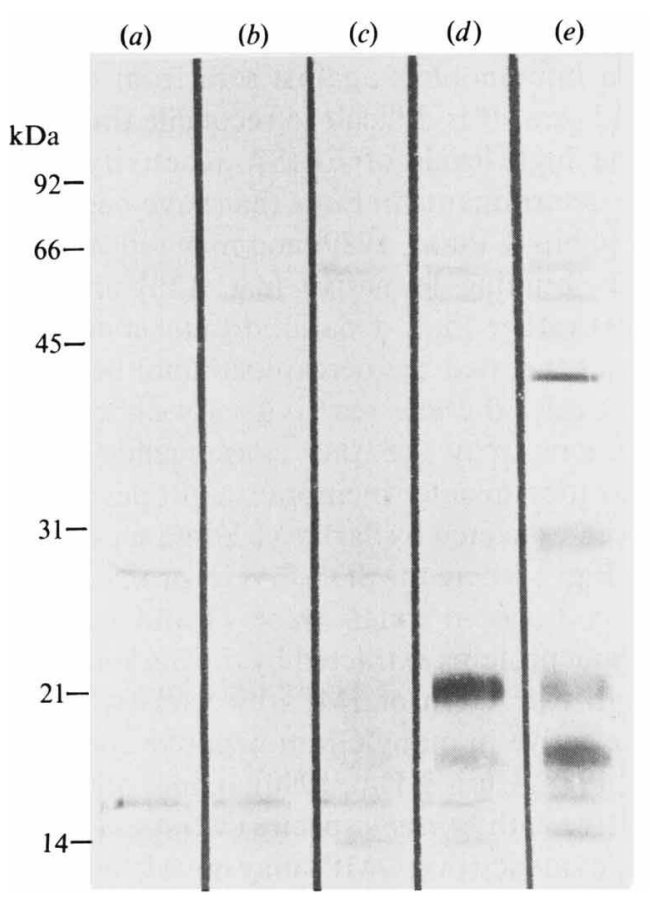

Fig. 3

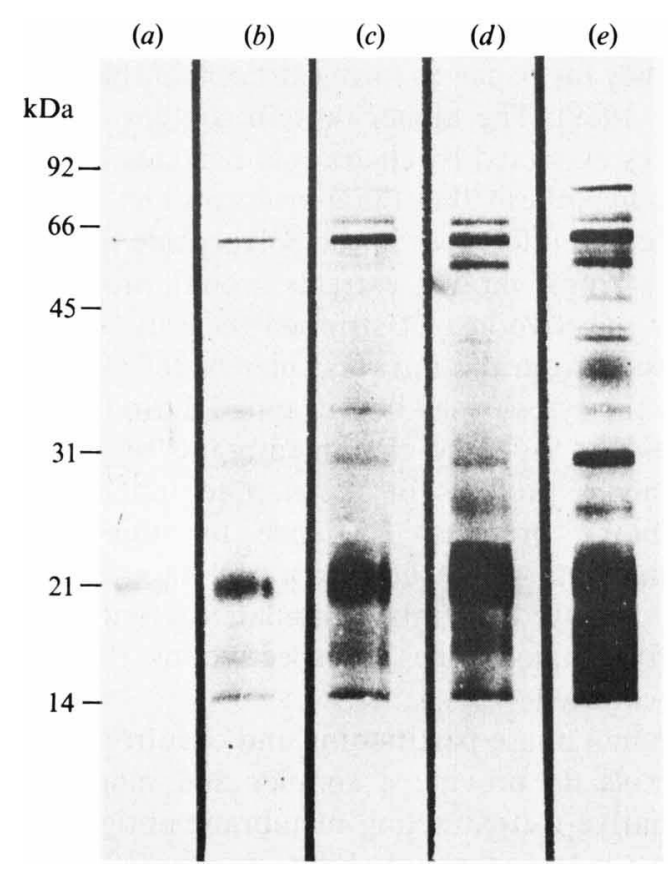

Fig. 5

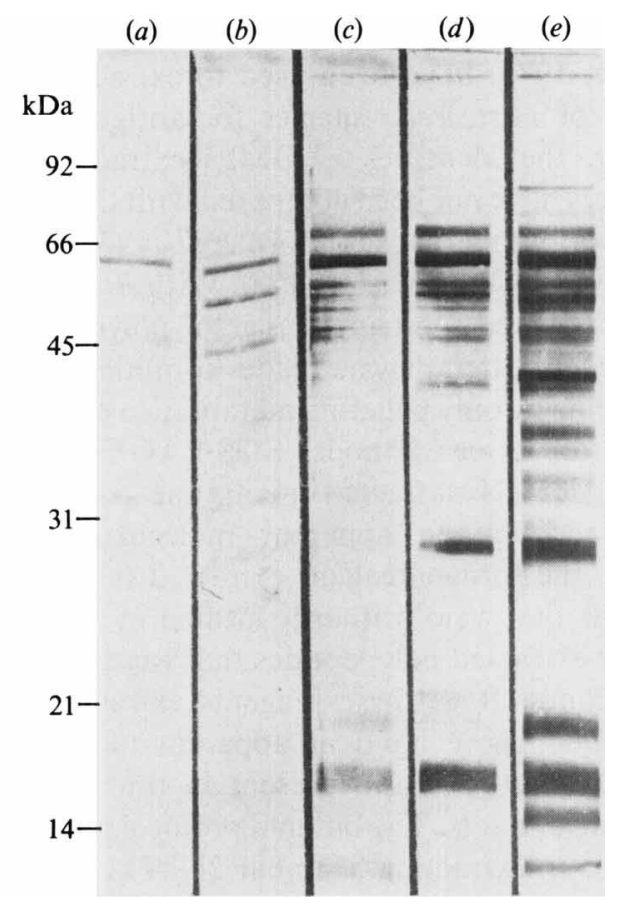

Fig. 4

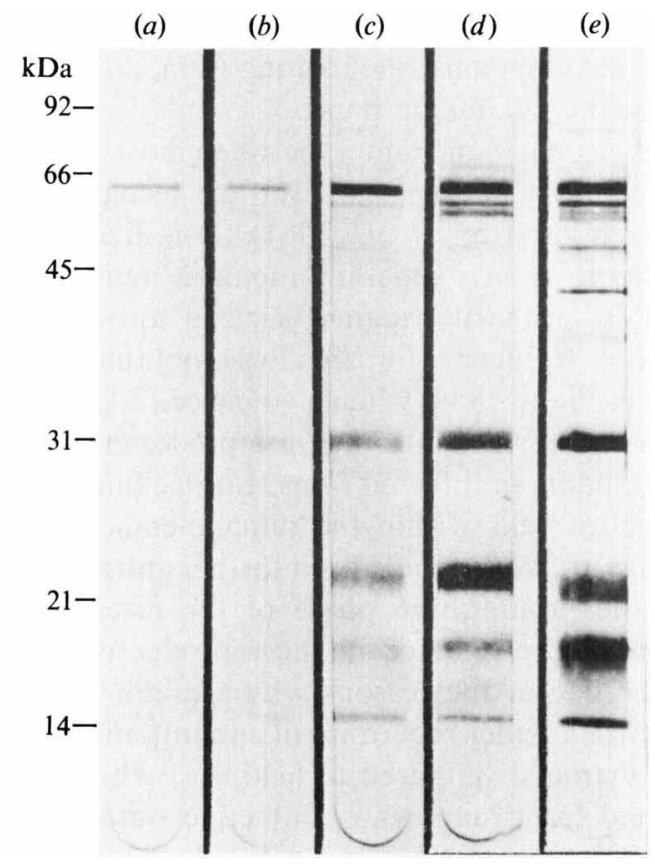

Fig. 6 


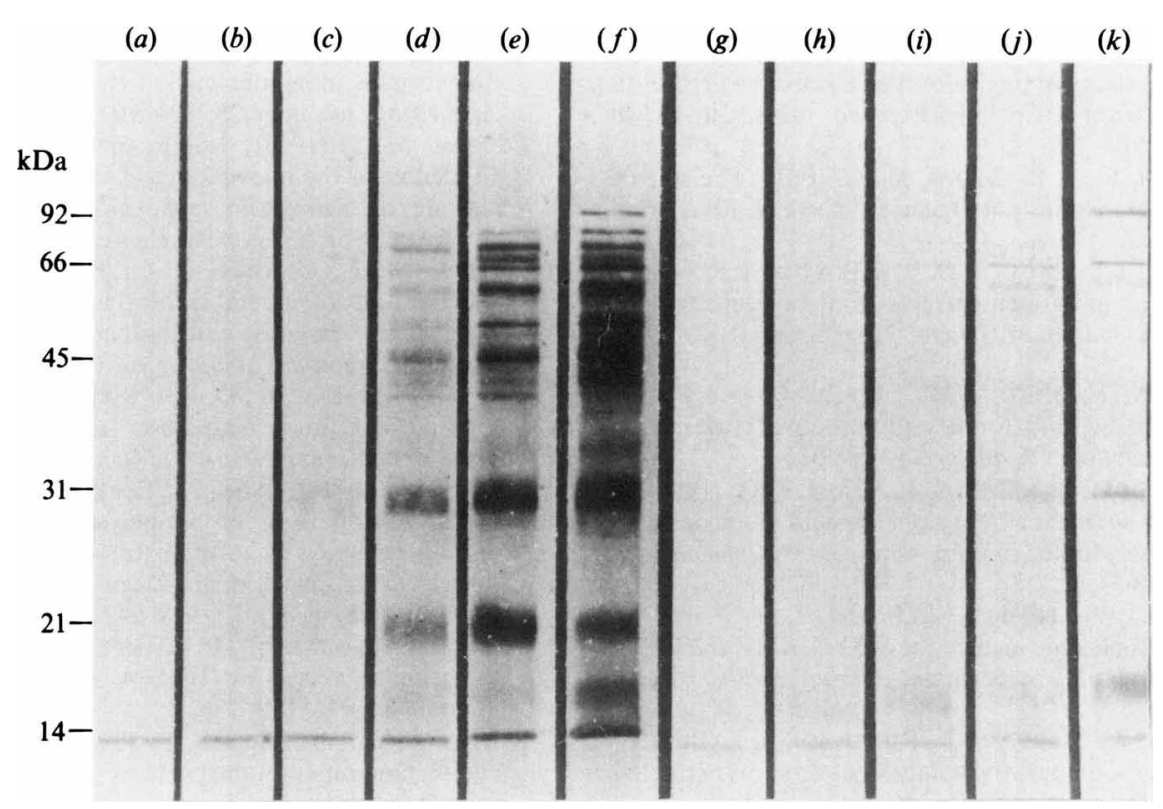

Fig. 7. Immunoblot depicting the target specificities of field sera against Sarkosyl-extracted membrane polypeptides and OMPs. Pooled sera (at a dilution of 1 in 250), representing reciprocal CF titres of 0 (lane $a$ ), 8 (lanes $b$ and $g$ ), 16 (lanes $c$ and $h$ ), 32 (lanes $d$ and $i$ ), 64 (lanes $e$ and $j$ ) and 128 (lanes $f$ and $k$ ) were reacted against boiled and mercaptoethanol-treated Sarkosyl extract (lanes $b-f$ ) or OMPs (lanes $g-k) ; 10 \mu \mathrm{g}$ of membrane antigen was loaded in each lane. Lane (a) represents pooled sera with a CF titre of 0 reacted against either Sarkosyl-extracted antigen or OMPs.

extraction of OMPs from $B$. ovis. The judicious use of membrane-enriched preparations described here will provide alternative reagents for ovine brucellosis serology, and may be useful as vaccines (Chin \& Plant, 1989).

The authors would like to thank Nadia Babicka and Joanne Loughlin for technical assistance, and Amanda Elston for bacterial propagation. This project was supported by a grant from the Wool Research Trust Fund (DAN 43P) on the recommendation of the Australian Wool Corporation.

\section{References}

Afzal, M., Brodie, S. J., Tengerdy, R. P. \& Squire, P. G. (1987). Isolation and antigenic reactivity of Brucella ovis outer membrane proteins. Journal of Clinical Microbiology 25, 2132-2135.
Bulgin, M. S. \& Anderson, B. C. (1983). Association of sexual experience with isolation of various bacteria in cases of ovine epididymitis. Journal of the American Veterinary Medical Association 182, 372-374.

BURGESS, G. W. (1982). Ovine contagious epididymitis: a review Veterinary Microbiology 7, 551-575.

CHIN, J. C. (1983). Comparison of different antigenic preparations for the detection of ovine serum antibodies against Brucella ovis by ELISA. Australian Veterinary Journal 60, 261-264.

ChIN, J. C. \& DAI, Y. (1990). Selective extraction of outer membrane proteins from membrane complexes of Pseudomonas maltophila by chloroform-methanol. Veterinary Microbiology 22, 69-78.

ChIN, J. C. \& PlanT, J. (1989). The temporal ELISA response of rams to Brucella ovis following experimental infection or vaccination. Research in Veterinary Science 46, 73-78.

ChIN, J. C. \& Scully, C. (1986). Identification of immunoreactive antigens of Brucella ovis by ELISA profiling. Research in Veterinary Science 41, 1-6.

ChIN, J. C. \& WATTS, J. E. (1988). Biological properties of phospholipase $\mathrm{C}$ purified from a fleecerot isolate of Pseudomonas aeruginosa. Journal of General Microbiology 134, 2567-2575.

Fig. 3. Immunoblot depicting the target specificities of field sera against membrane polypeptides extracted by SSC. Pooled sera (at a dilution of 1 in 250) representing reciprocal $\mathrm{CF}$ titres of $8,16,32,64$ and 128 in lanes $(a)-(e)$ were reacted against boiled and mercaptoethanol-treated membrane vesicles extracted by SSC (10 $\mu \mathrm{g}$ protein per lane).

Fig. 4. Immunoblot depicting the target specificities of field sera against membrane polypeptides extracted by KSCN. Pooled sera (at a dilution of 1 in 250), representing reciprocal $C F$ titres of $8,16,32,64$ and 128 in lanes $(a)-(e)$, were reacted against boiled and mercaptoethanol-treated membrane vesicles extracted by KSCN ( $10 \mu \mathrm{g}$ protein per lane).

Fig. 5. Immunoblot depicting the target specificities of field sera against membrane polypeptides extracted by butanol. Pooled sera (at a dilution of 1 in 250), representing reciprocal CF titres of 8,16,32, 64 and 128 in lanes $(a)-(e)$, were reacted against boiled and mercaptoethanol-treated membrane vesicles extracted by butanol ( $10 \mu \mathrm{l}$ protein per lane).

Fig. 6. Immunoblot depicting the target specificities of field sera against membrane polypeptides extracted by LAE. Pooled sera (at a dilution of 1 in 250), representing reciprocal CF titres of $8,16,32,64$ and 128 in lanes $(a)-(e)$, were reacted against boiled and mercaptoethanol-treated membrane vesicles extracted by LAE (10 $\mu \mathrm{g}$ protein per lane). 
Chin, J. C., Plant, J. \& Claxton, P. D. (1983). Evaluation of surface components of Brucella ovis as antigens for the detection of precipitin antibodies in serum from artificially exposed rams. Australian Veterinary Journal 60, 264-267.

Costerton, J. W., IRvin, R. T. \& Cheng, K. J. (1981). The role of bacterial surface structures in pathogenesis. Critical Reviews in Microbiology 8, 303-383.

Donachie, W., Gilmour, J. L., Mould, D. L. \& Poxton, I. R. (1984). Comparison of cell surface antigen extracts from two serotypes of Pasteurella haemolytica. Journal of General Microbiology 130, 12091216.

Dubois, M., Gilles, K. A., Hamilton, J. K., Rebers, P. A. \& Smith, F. (1956). Colorimetric method for determination of sugars and related substances. Analytical Chemistry 28, 350-356.

Ficht, T. A., Bearden, S. W., Sowa, B. A. \& Adams, L. G. (1988). A 36-Kilodalton Brucella abortus cell envelope protein is encoded by repeated sequences closely linked in the genomic DNA. Infection and Immunity 56, 2036-2046.

Filip, C., Fletcher, G., Wulff, J. L. \& Earhart, C. F. (1973). Solubilization of the cytoplasmic membrane of Escherichia coli by the ionic detergent sodium-lauryl sarcosinate. Journal of Bacteriology 115, 717-722.

Gamazo, C., Winter, A. J., Moriyon, I., Riezu-BoJ, J. I., Blasco, J. M. \& DiAZ, R. (1989). Comparative analyses of proteins extracted from hot saline or released spontaneously into outer membrane blebs from field strains of Brucella ovis and Brucella melitensis. Infection and Immunity 56, 1419-1426.

Goldman, R. C., White, D. \& Leive, L. (1981). Identification of outer membrane proteins including known lymphocyte mitogens as the endotoxin protein of E. coli. Journal of Immunology 127, 1290-1294.

HANCOCK, R. E. W. \& NikaIDO, H. (1978). Outer membranes of Gramnegative bacteria. XIX. Isolation from Pseudomonas aeruginosa PAOl and use in reconstitution and definition of the permeability barrier. Journal of Bacteriology 136, 381-390.

HARTLEY, W. J. (1955). Some observations on natural transmission of ovine brucellosis. New Zealand Veterinary Journal 3, 5-9.

HeCKels, J. E. (1981). Structural comparison of Neisseria gonorrhoeae outer membrane proteins. Journal of Bacteriology 145, 736-742.

Hicks, J. D., BURR, G. R., MARShall, D. R. \& VidLeR, B. M. (1978), CFT inaccurate for epididymitis. New Zealand Veterinary Journal 28 , 135.

LAEMMLI, U. K. (1970). Cleavage of structural proteins during the assembly of the head of bacteriophage T4. Nature, London 227, 680685.

McGowan, B. \& Schultz, G. (1956). Epididymitis in rams: clinical description and field aspects. Cornell Veterinarian 46, 277-281.

MYers, D. M., Jones, L. M. \& VAReLA-DiaZ, V. M. (1972). Studies of antigens for complement fixation and gel diffusion tests in the diagnosis of infections caused by Brucella ovis and other Brucella. Applied Microbiology 23, 894-902.

OsBoRN, M. J. (1963). Studies on the Gram-negative cell wall. I. Evidence for the role of 2-keto-3-deoxyoctonate in the lippopolysaccharide of Salmonella typhimurium. Proceedings of the National Academy of Sciences of the United States of America 50, 449-506.

Osborn, M. J., Gander, J. E., Parisi, E. \& Carson, J. (1972). Mechanisms of assembly of the outer membrane of Salmonella typhimurium: isolation and characterization of cytoplasmic and outer membrane. Journal of Biological Chemistry 247, 3962-3972.

PAGE, W. J. \& TAYLOR, D. E. (1988). Comparison of methods used to separate the inner and outer membranes of cell envelopes of Campylobacter spp. Journal of General Microbiology 134, 2925-2932.

Riezu-Boj, J. I., Moriyon, I., Blasco, J. M., Marin, C. M. \& Diaz, R. (1986). Comparison of lipopolysaccharide and outer membrane protein-lipopolysaccharide extracts in an enzyme-linked immunosorbent assay for the diagnosis of Brucella ovis infection. Journal of Clinical Microbiology 23, 938-942.

RYu, H. \& KaEberLe, M. L. (1986). Immunogenicity of potassium thiocyanate extract of type A Pasteurella multocida. Veterinary Microbiology 11, 373-385.

Santos, J. M., Verstreate, D. R., Perera, V. Y. \& Winter, A. J. (1984). Outer membrane proteins from rough strains of four Brucella species. Infection and Immunity 46, 188-194.

Schnaitman, C. A. (1970). Protein composition of the cell wall and cytoplasmic membrane of Escherichia coli. Journal of Bacteriology 104, 890-891.

SchNaItMAN, C. A. (1971). Effect of ethylenediaminetetraacetic acid, Triton X-100, and lysozyme on the morphology and chemical composition of isolated cell walls of Escherichia coli. Journal of Bacteriology 104, 553-563.

SEARSON, J. E. (1982). Sensitivity and specificity of two microtiter complement fixation tests for the diagnosis of Brucella ovis infection in rams. Australian Veterinary Journal 58, 5-7.

Towbin, H., Staehelin, T. \& GoRdon, J. (1979). Electrophoretic transfer of proteins from polyacrylamide gels to nitrocellulose sheets: procedure and some applications. Proceedings of the National Academy of Sciences of the United States of America 76, 4350-4354.

Verstreate, D. R. \& WinTER, A. J. (1984). Comparison of sodium dodecyl sulfate-polyacrylamide gel electrophoresis profiles and antigenic relatedness among outer membrane proteins of 49 Brucella abortus strains. Infection and Immunity 46, 182-187.

Verstreate, D. R., Creasy, M. T., Caveney, N. T., Baldwin, C. L., BLAB, M. W. \& WINTER, A. J. (1982). Outer membrane proteins of Brucella abortus: isolation and characterization. Infection and Immunity 35, 979-989. 